\title{
Immunocompromised children and young people are at no increased risk of severe COVID-19
}

\author{
H. Chappell ${ }^{\mathrm{a}}$, R. Patel ${ }^{\mathrm{b}}$, C. Driessens ${ }^{\mathrm{c}}$, A.W. Tarr ${ }^{\mathrm{d}, \mathrm{e}, \mathrm{g}}$, W.L. Irving ${ }^{\mathrm{d}, e, g}$, P.J. Tighe ${ }^{\mathrm{d}, \mathrm{e}}$, \\ H.J. Jackson ${ }^{e}$, T. Harvey-Cowlishaw ${ }^{e}$, L. Mills ${ }^{a}$, M. Shaunak ${ }^{a}$, D. Gbesemete ${ }^{\mathrm{a}, \mathrm{b}}$, A. Leahy $^{\mathrm{f}}$, \\ J.S. Lucas ${ }^{\mathrm{a}, \mathrm{b}, \mathrm{f}}$, S.N. Faust ${ }^{\mathrm{a}, \mathrm{b}, \mathrm{f}}$, H. de Graaf ${ }^{\mathrm{a}, \mathrm{b}, \mathrm{f}, 1, *}$ \\ ${ }^{a}$ NIHR Southampton Clinical Research Facility and Biomedical Research Centre, University Hospital Southampton NHS Trust, Tremona Road, Southampton \\ SO16 6YD, UK \\ ${ }^{\mathrm{b}}$ Faculty of Medicine and Institute for Life Sciences, University of Southampton, Southampton SO16 6YD, UK \\ ${ }^{c}$ NIHR Applied Research Collaboration Wessex, University Hospital Southampton NHS Trust, Southampton SO16 6YD, UK \\ d NIHR Nottingham Biomedical Research Centre, Nottingham University Hospitals NHS Trust and the University of Nottingham, Nottingham, UK \\ e School of Life Sciences, University of Nottingham, Nottingham NG7 2RD, UK \\ ${ }^{\mathrm{f}}$ Paediatric Medicine, University Hospital Southampton NHS Trust, Southampton SO16 6YD, UK \\ ${ }^{\mathrm{g}}$ Wolfson Centre for Global Virus Research
}

\section{A R T I C L E I N F O}

\section{Article history:}

Accepted 9 November 2021

Available online 14 November 2021

\section{Keywords:}

SARS-CoV-2

COVID-19

Children

Immunocompromised

\begin{abstract}
S U M M A R Y
Objectives: We aimed to prospectively describe the incidence and clinical spectrum of SARS-CoV-2 infection in immunocompromised paediatric patients in the UK.

Methods: From March 2020 to 2021 weekly questionnaires were sent to immunocompromised paediatric patients or their parents. Information, including symptom presentation and SARS-CoV-2 PCR test results, was collected from 1527 participants from 46 hospitals. Cross-sectional serology was investigated in February and March 2021.

Results: Until the end of September 2020, no cases were reported. From September 28th 2020 to March 2021 a total of 38 PCR-detected SARS-CoV-2 infections were reported. Of these, four children were admitted to hospital but none had acute severe COVID-19. Increasing age in association with immunodeficiency increased reporting of SARS-CoV-2 infection. Worsening of fever, cough, and sore throat were associated with participants reporting SARS-CoV-2 infection. Serology data included 452 unvaccinated participants. In those reporting prior positive SARS-CoV-2 PCR, there were detectable antibodies in 9 of 18 (50\%). In those with no prior report of infection, antibodies were detected in 32 of 434 (7•4\%).

Conclusions: This study shows SARS-CoV-2 infections have occurred in immunocompromised children and young people with no increased risk of severe disease. No children died.
\end{abstract}

(c) 2021 The British Infection Association. Published by Elsevier Ltd. All rights reserved.

\section{Introduction}

Studies from the United Kingdom and worldwide have shown that children and young people have made up a small proportion of those infected with severe acute respiratory syndrome coronavirus 2 (SARS-CoV-2). Less than $5 \%$ of total case numbers were in children in studies from Italy $(1 \bullet 2 \%){ }^{1}$ USA $(1 \bullet 7 \%),{ }^{2}$ China $(2 \cdot 2 \%),{ }^{3}$ and UK $(3 \bullet 9 \%){ }^{4}$ Due to subclinical and variable presentation in those under 18 years, rates may be under reported in children and

\footnotetext{
* Corresponding author at: NIHR Southampton Clinical Research Facility and Biomedical Research Centre, University Hospital Southampton NHS Trust, Paediatric Rheumatology, Tremona Road, Southampton SO16 6YD, UK.

E-mail address: h.de-graaf@soton.ac.uk (H. de Graaf)

1 On behalf of the ImmunoCOVID19 study group (Appendix A)
}

so paediatric seroprevalence studies are vital. ${ }^{5-7}$ In the UK, seroprevalence rates in children under 18 were estimated to be between 5 and $10 \%$ during the pandemic first wave. ${ }^{7}$ Seropositivity rates in children have been found to be comparable to overall rates and variable between countries. For example, seroprevalence studies show rates in $0-17$ year olds in the USA of $2 \cdot 7 \%$ during the first wave compared to $3 \cdot 4 \%$ overall, ${ }^{8}$ whereas in China they were found to be $3 \bullet 6 \%$ versus $5 \bullet 6 \%$ overall. $^{9}$ In Switzerland the seroprevalence in 5-19 year olds after the first wave was $7 \cdot 3 \%$, compared to $7 \cdot 9 \%$ overall, ${ }^{10}$ rising to $20 \cdot 2 \%$ in $0-17$ year olds after the second wave, compared to $20 \cdot 5 \%$ overall. ${ }^{11}$ The UK "What's the STORY" trial reported seroprevalence rates in 1-19 year olds of $0 \%$ in February and March 2020 , rising to $4 \cdot 2 \%$ in April and $4 \bullet 0 \%$ in May. ${ }^{12}$ 
Large multicentre cohort studies from USA, UK, and Europe show low overall numbers of paediatric hospital admissions due to coronavirus disease 2019 (COVID-19) with a low proportion of these being admitted to paediatric intensive care units. $5,13,14$ These cohort studies and national data from USA, UK, Italy, Germany, Spain, France, and South Korea show that COVID-19 mortality risk is low in children and young people. ${ }^{15}$

Parents, clinicians, and public health bodies globally have remained concerned about risk of SARS-CoV-2 infection to children and young people living with chronic health conditions. In the absence of paediatric data, many immunocompromised children and young people in the UK were initially deemed "extremely vulnerable" to the effects of SARS-CoV-2 infection. Against the advice of many specialist clinicians and NICE, ${ }^{16}$ many individuals were advised to adopt specific precautionary "shielding" measures, were subject to school closures, and have had reduced access to healthcare, causing significant burden on both them and their families. ${ }^{17,18}$

Evidence on the risks of SARS-CoV-2 in immunocompromised paediatric patients is beginning to emerge. A large systematic review with meta-analysis and a large retrospective cross sectional study, found paediatric patients with chronic health conditions were at higher risk of severe COVID-19 compared to those without. ${ }^{19,20}$ However, rates of serious disease (relative risk ratio $1 \bullet 79$ $(95 \%$ CI $1 \cdot 27-2 \cdot 51))^{19}$ were very small in proportion to other causes of morbidity and mortality in children ${ }^{15}$ and only 26/9353 children with comorbidities had immune disorders. ${ }^{19}$ To accurately understand and assess the risk in cohorts of immunocompromised paediatric patients, further population and serology studies are required. Currently there are a limited number of studies reporting seroprevalence in immunocompromised paediatric patients ${ }^{21-25}$ although some studies have not yet been reported. ${ }^{26,27}$

We aimed to prospectively describe the incidence and clinical spectrum of SARS-CoV-2 infection in a UK-wide cohort of immunocompromised children and young people. A secondary aim was to characterise risk factors and predictive symptoms for SARS-CoV-2 infection in this cohort.

\section{Materials and methods}

This prospective cohort study was carried out over one year (16th March 2020-14th March 2021) and included immunocompromised children and young people under the age of 19 years. Immunocompromise was defined as having any medical indication for an annual influenza vaccine, in keeping with UK public health guidelines. ${ }^{28}$ Participants were recruited from 46 hospitals across the UK between March and July 2020. Participants and parents received information sheets electronically with a link to an online consent form. They received electronic reminders and were removed from the study database after three weeks in the absence of consent. Participants who had consented to participate in the study were asked to complete an online questionnaire every week, with questions based on the ISARIC and WHO COVID-19 Case Report Form. ${ }^{29}$ Information was collected regarding symptom presentation, test results, health care attendance, hospital admission, and the effects of COVID-19 on daily life. Results from the first four months of the study have been published. ${ }^{18}$

Participants self-reported when a SARS-CoV-2 PCR test was carried out and found to be positive. These tests were sought according to UK government guidelines with testing capacity increasing through the study period. Initially testing was limited to hospital admissions. From 18th May 2020 those aged over five years with symptoms could seek a test and from 27th May 2020 testing was expanded to those under five years and contact tracing begun. ${ }^{30,31}$ Participants reporting positive PCR swabs were emailed to clarify result and clinical outcomes.
The study gained ethical approval from the Yorkshire and the Humber - Leeds West NHS Research Ethics Committee (IRAS 281544).

\section{Cohort}

1645 participants consented to the study. Of these, 1527 successfully completed at least one weekly questionnaire. A further 505 were withdrawn during the study period (Fig. 1). The commonest reason for withdrawal was not completing the survey for three successive weeks. At week 32, the study team started contacting participants who had not completed questionnaires for three successive weeks regarding ongoing participation. This led to a sharp rise in withdrawals. Median age was 11 years (range 018). $55 \bullet 1 \%$ of participants were female. Baseline characteristics are displayed in Table 1.

\section{Serology}

Between December 2020 and January 2021 all participants ( $n=1073$ ) were invited to take part in an optional serology substudy. They were provided with information sheets electronically with a link to an online consent form. Consenting participants were sent sampling kits via post between February and March 2021. Participants collected a dried blood sample using a safety lancet and Mitra ${ }^{\circledR}$ sampling device. Validated in-house enzymelinked immunosorbent assays (ELISA) were carried at the virology laboratories of the University of Nottingham to detect SARS-CoV-2 anti-nucleocapsid and anti-spike IgG antibodies, as previously described. ${ }^{32}$ All assays were performed on Opentrons OT-2 Precision liquid handling robots (full protocol available on request). Original assay validations were performed on a separate sample set using commercial anti-S1 (Euroimmun) and anti-N assays (Roche) and conducted at the Rare and Imported Pathogens Laboratory at Public Health England using manufacturers' protocols.

Antibodies were first extracted from dried samples to a 1:15 dilution by shaking for $2 \mathrm{~h}$ in $150 \mu \mathrm{L}$ phosphate buffered saline (PBS) containing $0 \bullet 1 \%$ Triton-x100 and $0 \bullet 05 \%$ sodium azide. Extracted samples were diluted to $1: 120$ with $3 \%$ skimmed milk powder in PBS containing $0 \bullet 05 \%$ Tween 20 and $0 \bullet 05 \%$ sodium azide.

ELISAs were performed by coating 384 well NUNC maxisorp plates (Thermofisher) with either $20 \mu \mathrm{L} /$ well of $0.5 \mu \mathrm{g} / \mathrm{mL}$ of SARS-CoV-2 spike protein S1 subunit (His-tagged; Sinobiologicals, $\mathrm{GmbH}$ ) or SARS-CoV-2 Nucleocapsid (His-Tagged; Sinobiologicals, $\mathrm{GmbH}$ ) in carbonate-bicarbonate buffer (CBC; Merck UK), sealing with foil film and incubating overnight at $4{ }^{\circ} \mathrm{C}$. Wells were then washed three times with $100 \mu \mathrm{L}$ PBS with $0 \bullet 05 \%$ Tween 20 (PBST) using a Thermofisher Wellwash Versa plate washer with a final aspirate. Wells were immediately filled with $100 \mu \mathrm{L}$ of $3 \%$ skimmed milk powder $(\mathrm{w} / \mathrm{v})$ in PBS and $0 \bullet 05 \%$ sodium azide, foil sealed and blocked overnight at $4{ }^{\circ} \mathrm{C}$. Assay plates were then washed three times as before and duplicate wells filled with $20 \mu \mathrm{L}$ of the 1:120 diluted sample, diluted in $3 \%$ skimmed milk powder $(w / v)$ in PBS and $0 \bullet 05 \%$ sodium azide.

Control samples included duplicates of a 1:120 dilution of a pool of sera derived from 32 individuals previously identified as having high nucleocapsid and high spike S1 reactivity. Three negative samples, each derived from a separate pool of 21 pre-covid sera were added to separate wells in duplicate. Wells containing only dilution buffer were used as non-serum blank. After 15 min incubation at room temperature $\left(21^{\circ} \mathrm{C}\right)$, the plate was washed three times in PBST. This was followed by addition to each well of $20 \mu \mathrm{L}$ of gamma chain-specific anti-human IgG-HRP conjugate (Sigma A0170-1ML) at 1:30,000 dilution in PBST and incubation for $15 \mathrm{~min}$ at room temperature. Wells were then washed three 


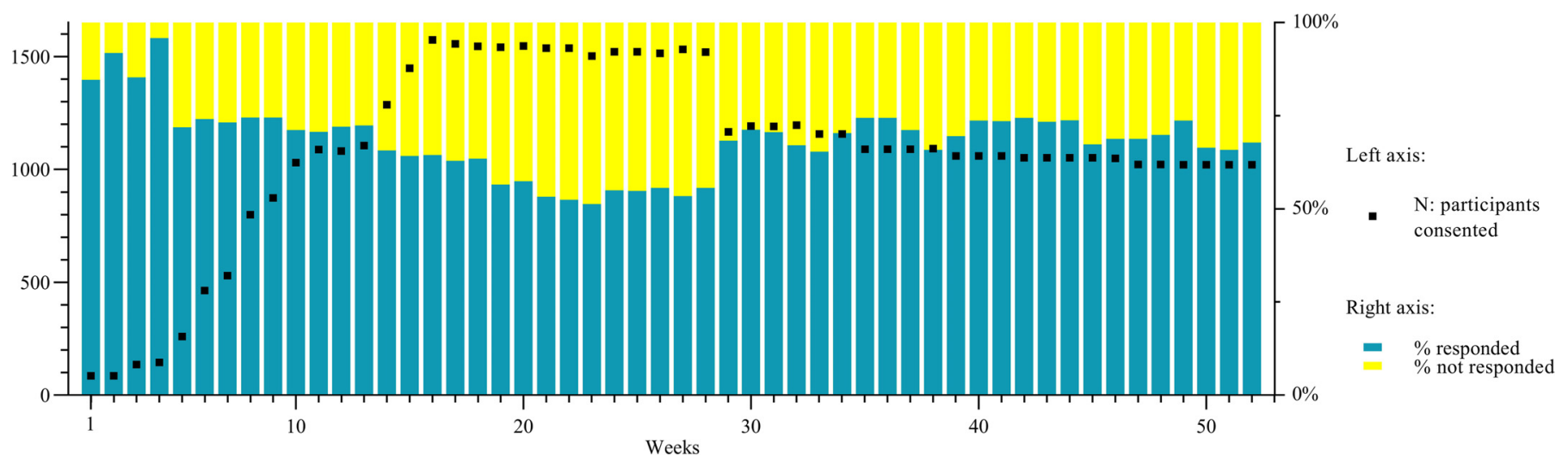

Fig. 1. Weekly participant numbers and weekly questionnaire response rate (16th March 2020-14th March 2021).

Table 1

Characteristics of participants referred to the ImmunoCOVID study.

\begin{tabular}{|c|c|c|c|c|}
\hline & $\begin{array}{l}\text { Referred but not } \\
\text { participating }\end{array}$ & $\begin{array}{l}\text { Withdrawn } \\
\text { participants }\end{array}$ & $\begin{array}{l}\text { Currently active } \\
\text { participants }\end{array}$ & $\begin{array}{l}\text { COVID positive } \\
\text { (subset) }\end{array}$ \\
\hline Sample size & 1373 & 505 & 1022 & 38 \\
\hline Female & $53 \bullet 8 \%$ & $54 \bullet 5 \%$ & $55 \bullet 1 \%$ & $55 \cdot 3 \%$ \\
\hline Teenagers & $64 \bullet 4 \% * * *$ & $55 \bullet 6 \%$ & $55 \%$ & $68 \bullet 4 \%$ \\
\hline Age & $11 \bullet 9+4 \bullet 3^{* * *}$ & $10 \bullet 8+4 \bullet 4$ & $10 \bullet 7+4 \bullet 3$ & $12 \bullet 6+4 \bullet 2^{* *}$ \\
\hline UK geography & $* * *$ & $*$ & & \\
\hline South & $9 \bullet 9 \%$ & $16 \bullet 6 \%$ & $21 \bullet 4 \%$ & $18 \bullet 4 \%$ \\
\hline Middle & $44 \bullet 0 \%$ & $41 \bullet 1 \%$ & $42 \bullet 1 \%$ & $47 \bullet 4 \%$ \\
\hline North & $46 \bullet 1 \%$ & $42 \cdot 3 \%$ & $36 \bullet 5 \%$ & $34 \bullet 2 \%$ \\
\hline \multicolumn{5}{|l|}{ Treatment team } \\
\hline Rheumatology & $42 \bullet 8 \%$ & $48 \cdot 2 \%$ & $48 \cdot 7 \%$ & $52 \bullet 6 \%$ \\
\hline Immunology & $8 \bullet 1 \%$ & $10 \bullet 4 \%$ & $9 \bullet 3 \%$ & $13 \bullet 2 \%$ \\
\hline Respiratory & $7 \bullet 7 \%$ & $6 \bullet 3 \%$ & $5 \bullet 1 \%$ & $5 \cdot 3 \%$ \\
\hline Oncology & $5 \bullet 3 \%$ & $2 \bullet 6 \%$ & $4 \bullet 3 \%$ & $7 \bullet 9 \%$ \\
\hline Gastroenterology & $7 \bullet 5 \%$ & $8 \cdot 3 \%$ & $9 \bullet 7 \%$ & $2 \bullet 6 \%$ \\
\hline Nephrology & $11 \bullet 7 \%$ & $12 \%$ & $10 \cdot 7 \%$ & $7 \bullet 9 \%$ \\
\hline Neurology & $3 \bullet 1 \%$ & $3 \bullet 9 \%$ & $2 \bullet 2 \%$ & $0 \%$ \\
\hline Haematology & $3 \bullet 7 \%$ & $1 \bullet 6 \%$ & $2 \cdot 3 \%$ & $2 \bullet 6 \%$ \\
\hline Neonatology & $0 \bullet 3 \%$ & $0 \cdot 2 \%$ & $0 \bullet 2 \%$ & $0 \%$ \\
\hline Diabetes & $7 \cdot 3 \%$ & $5 \bullet 1 \%$ & $5 \bullet 3 \%$ & $5 \bullet 3 \%$ \\
\hline Infection & $2 \bullet 0 \%$ & $0 \bullet 4 \%$ & $0 \bullet 4 \%$ & $2 \bullet 6 \%$ \\
\hline Dermatology & $0 \bullet 5 \%$ & $0 \bullet 8 \%$ & $0 \bullet 9 \%$ & $0 \%$ \\
\hline Heart and Lung & $0 \bullet 1 \%$ & $0 \cdot 2 \%$ & $0 \bullet 6 \%$ & $0 \%$ \\
\hline \multicolumn{5}{|l|}{ Diagnosis } \\
\hline Gastroenterology & & $10 \bullet 7 \%$ & $13 \bullet 1 \%$ & $0 \% *$ \\
\hline Nephrology & & $11 \%$ & $9 \%$ & $10 \bullet 8 \%$ \\
\hline Transplants & & $7 \bullet 4 \%$ & $7 \bullet 6 \%$ & $13 \bullet 5 \%$ \\
\hline Diabetes & & $6 \bullet 4 \%$ & $6 \bullet 5 \%$ & $5 \bullet 4 \%$ \\
\hline Immunodeficiency & & $10 \bullet 3 \%$ & $8 \bullet 7 \%$ & $18 \bullet 9 \%$ \\
\hline Oncology & & $5 \bullet 6 \%$ & $7 \bullet 7 \%$ & $10 \bullet 8 \%$ \\
\hline Respiratory & & $7 \cdot 2 \%$ & $8 \bullet 5 \%$ & $8 \bullet 1 \%$ \\
\hline Other & & $29 \bullet 1 \%$ & $26 \bullet 7 \%$ & $29 \bullet 7 \%$ \\
\hline Juvenile Idiopathic & & $37 \bullet 4 \%$ & $35 \bullet 4 \%$ & $40 \bullet 5 \%$ \\
\hline Arthritis & & $15 \bullet 5 \%$ & $18 \cdot 5 \%$ & $16 \bullet 2 \%$ \\
\hline \multicolumn{5}{|l|}{$\begin{array}{l}\text { Other immune } \\
\text { condition }\end{array}$} \\
\hline \multicolumn{5}{|l|}{ Medication } \\
\hline Other drugs & & $49 \%$ & $53 \bullet 7 \%$ & $58 \bullet 8 \%$ \\
\hline Chemotherapy & & $0 \bullet 9 \%$ & $0 \bullet 8 \%$ & $0 \%$ \\
\hline Antibiotics & & $16 \bullet 6 \%$ & $16 \%$ & $16 \bullet 7 \%$ \\
\hline Other & & $16 \bullet 7 \% *$ & $21 \bullet 6 \%$ & $23 \bullet 7 \%$ \\
\hline immunosuppressants & & $17 \bullet 5 \%$ & $19 \%$ & $16 \bullet 7 \%$ \\
\hline Systemic & & $34 \bullet 7 \%$ & $35 \bullet 1 \%$ & $25 \%$ \\
\hline corticosteroids & & $27 \bullet 2 \%$ & $29 \cdot 3 \%$ & $27 \bullet 8 \%$ \\
\hline \multicolumn{5}{|l|}{ Biologics } \\
\hline Methotrexate & & & & \\
\hline
\end{tabular}

Statistical significance is calculated with Chi-Square statistics. If one or more cells in the contingency table had an expected count of less than five the Fisher's exact statistic was calculated. Group differences in age were calculated with $\mathrm{F}$ test.

* significant at $0 \bullet 05$ level.

** significant at $0 \bullet 01$ level.

*** significant at $0 \bullet 001$ level. 
times in PBST. $40 \mu \mathrm{L}$ of One-step ultraTMB substrate solution (Thermofisher) was added to each well. After 20 min incubation at room temperature, $40 \mu \mathrm{L}$ of $2 \mathrm{~N} \mathrm{H} 2 \mathrm{SO} 4$ was added to each well and the 384 well plate read at $450 \mathrm{~nm}$ absorption in a GlowMax Explorer microplate reader (Promega Corp.). Data from absorbance measurements were output to Excel data sheets and subsequently imported into Graphpad Prism for basic analysis. More detailed statistical analysis was then carried out on SPSS.

Seropositivity was indicated according to the ratio method (i.e. ratio of the average sample optical density/average Negative optical density). According to this approach a ratio of $>=1 \bullet 1$ was classified as positive and a ratio of $<1 \bullet 1$ was classified as negative.

\section{Statistical analysis}

Data cleaning, formatting, and analyses were performed with SAS 9.4 (SAS Institute INC, Cary NC). Survival analysis techniques were used to explore the risk of SARS-CoV-2 infection, as measured by PCR testing, to participants throughout the first year of the study. The semi-parametric methodology of Cox regression (Cox, 1972) was employed. Factors associated with the risk of SARS-CoV-2 infection were determined. In addition, the symptoms uniquely experienced at time of SARS-CoV-2 infection were determined. For analysis purposes we have treated infection as a non-repeated event. Data was collected on a weekly basis, creating ties in the data. Parameters are therefore estimated using the estimation method developed by Efron (1977). Participant information was only collected from participants during the study period from recruitment to the last data received (when they may have chosen to withdraw formally or informally). Data prior to the first questionnaire and beyond the last questionnaire received per participant is unknown and is described as having been censored. Every individual was considered at risk of SARS-CoV-2 infection when they entered the study until they either were infected or were censored. To control for late entry, participants' risk for infection was determined between study entry and withdrawal or finish time. We assume that censoring due to withdrawal is noninformative, but receiving "other immunosuppressants" (azathioprine, tacrolimus or mycophenolate mofetil) has been included in the survival model as participants receiving these treatments were less likely to withdraw from the study.

\section{Role of the funding source}

The funders had no role in study design, data collection, data analysis, data interpretation, or writing of the manuscript. The corresponding author had full access to all data and had final responsibility for the decision to submit for publication.

\section{Results}

\section{PCR confirmed cases}

Participants reported a total of 1355 PCR tests through the study period. The majority of participants $(919,60 \cdot 2 \%)$ did not report any PCR tests. $576(37 \bullet 8 \%)$ reported between 1 and 5 tests and 2\% reported between 6 and 20 tests. During the government advised shielding period (March-August 2020) no SARS-CoV-2 infections were reported. The first positive SARS-CoV-2 PCR test was in week 30 (28th September-5th October). Further positive tests were subsequently reported, with peaks in rates in weeks 36 (9th15th November 2020) and 42 (21st-27th December 2020) with five and six cases, respectively (Fig. 2). There were a total of 38 PCR detected SARS-CoV-2 infections, giving an incidence rate of $3 \cdot 7 \%$ $(n=1022)$. Of these six were asymptomatic, 28 had symptoms managed at home, and four reported hospital admission. Those reporting hospital admissions are described in Table 2. These participants all had varying presentations and significant underlying comorbidities and therapies; two were transplant patients, one had acute lymphoblastic leukaemia, and one had X-linked agammaglobulinemia. Clinical presentation was varied but none reported acute severe COVID-19 or paediatric multisystem inflammatory syndrome. None were admitted to paediatric intensive care units or died.

\section{Hazard analysis}

Assuming that hazard remained constant between August 2020 and March 2021, an estimate of hazard across the whole cohort is $0 \cdot 00,148$ or $38 / 25,687$ (number of cases/ total number of answered questionnaires). This is equivalent to a positive SARS-CoV2 PCR test once every 676 weeks. This hazard was in the context of varying disease incidence during the pandemic, and varying approaches of participants to shielding or not. While NHS electronic systems sent text messages telling children and young people designated "at risk" to shield based on adult diagnostic categories and the assumed risk, many specialist clinicians advised school attendance to children with all but the most severe immune problems. ${ }^{16}$

The significance of different demographic (sex, age, geographical region), diagnosis and medication use covariates, as well as time-dependent symptom covariates were tested. The best multivariate model is presented in Table 3. Schoenfeld residuals were checked to determine any violations in the proportional hazard assumption. OLS regression models of the residuals for age and immune deficiency disorder did not show departure from proportionality for those variables.

The Cox regression model indicates for each additional year of age the hazard of infection goes up $13 \%$. Having an immunodeficiency increases hazard of infection almost three times. Those individuals who reported positive PCR tests were more likely than other participants to report worsening of fever, cough, and sore throat symptoms during the same week.

\section{Serology}

478 participants provided serology samples and their baseline characteristics are displayed in Table 4. However, participants in this cohort were not representative of those overall. Young people over ten years, those with "other diagnoses" or diabetes; and those on "other drugs", biologics or methotrexate were more likely to take part in this sub-study. There was also geographical variation in participation. Rates by vaccination status in all and by sex, age, and prior PCR status in those unvaccinated are displayed in Table 5 .

26 participants reported receiving a first dose of a COVID vaccine prior to serology. Of these, six $(23 \bullet 1 \%)$ were serologically positive with a mean of 23 days between vaccination and sampling (range 14-33). Three of these were positive for only anti-S1 IgG and three positive for both anti-S1 and anti-N IgG. Those who were negative had a mean of $15 \bullet 65$ days between vaccination and sampling (range 1-42). Vaccinated participants were excluded from further analysis.

Of 452 unvaccinated participants, anti-N and/or anti-S antibodies were detected in 41 samples $(9 \bullet 1 \%)$. Of those participants reporting a prior positive PCR test 18 took part in the serology substudy and of these, antibodies were detected in nine (50\%). Four of these were positive for only anti-N IgG, one positive for only anti-S1 IgG, and four positive for both anti-N and anti-S1 IgG. In those with no previous positive PCR test, antibodies were detected in 32 of $434(7 \cdot 4 \%)$. Seventeen of these were positive for only anti$\mathrm{N}$ IgG, six positive for only anti-S1 IgG, and nine positive for both 


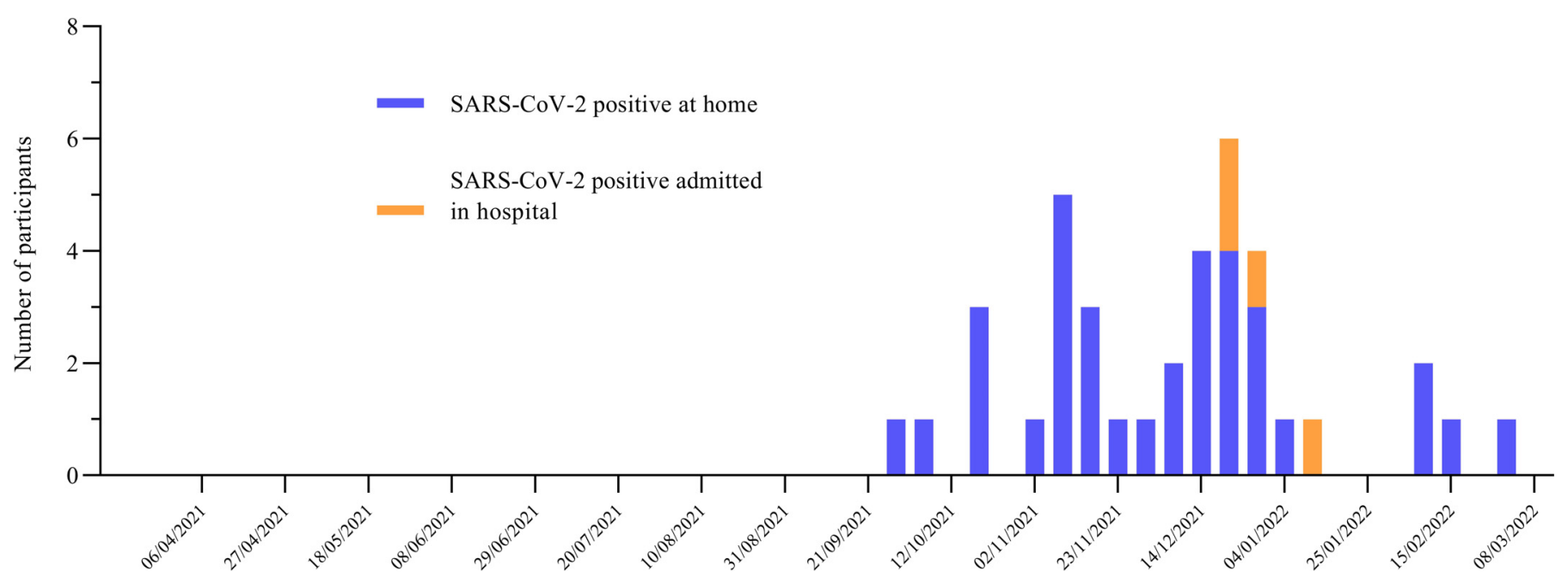

Fig. 2. Number of participant SARS-CoV-2 infections by week (16th March 2020-14th March 2021).

Table 2

Description of PCR positive SARS-CoV-2 infection reporting hospital admission.

\begin{tabular}{|c|c|c|c|c|c|c|}
\hline $\begin{array}{l}\text { Week of } \\
\text { PCR }\end{array}$ & $\begin{array}{l}\text { Week of } \\
\text { admission }\end{array}$ & $\begin{array}{l}\text { Age in } \\
\text { years }\end{array}$ & Sex & Admission Details & Past Medical History & Baseline Medication \\
\hline 42 & 42 & 17 & Male & $\begin{array}{l}\text { Admitted with negative PCR, } \\
\text { symptoms of bowel } \\
\text { obstruction and underwent } \\
\text { laparotomy. Asymptomatically } \\
\text { tested positive prior to } \\
\text { discharge. Subsequently } \\
\text { readmitted with fever and } \\
\text { abdominal pain for three days } \\
\text { before symptom resolution. } \\
\text { Subsequent serology negative. }\end{array}$ & $\begin{array}{l}\text { liver transplant, } \\
\text { atypical haemolytic } \\
\text { uraemic syndrome, } \\
\text { chronic kidney disease, } \\
\text { and superior vena cava } \\
\text { stenosis }\end{array}$ & $\begin{array}{l}\text { prednisolone, } \\
\text { sirolimus, } \\
\text { mycophenolate } \\
\text { mofetil, hydralazine, } \\
\text { doxazosin, amlodipine, } \\
\text { losartan, atenolol, } \\
\text { allopurinol, and } \\
\text { desloratadine }\end{array}$ \\
\hline 42 & 44 & 12 & Male & $\begin{array}{l}\text { Initially tested positive with } \\
\text { only symptom being } \\
\text { abdominal pain. Subsequently } \\
\text { admitted for two days with } \\
\text { bacterial chest infection. Put } \\
\text { down to post viral } \\
\text { immunosuppression. } \\
\text { Admission swab negative. } \\
\text { Subsequent serology negative. }\end{array}$ & heart transplant & $\begin{array}{l}\text { sirolimus, } \\
\text { mycophenolate } \\
\text { mofetil, pravastatin, } \\
\text { and melatonin }\end{array}$ \\
\hline 43 & 52 & 17 & Male & $\begin{array}{l}\text { Tested positive, initially } \\
\text { managed at home with } \\
\text { antibiotics. Subsequently had } \\
\text { persistent fever leading to } \\
\text { investigation with } \\
\text { bronchoscopy which showed } \\
\text { changes consistent with } \\
\text { SARS-CoV-2 infection. Five day } \\
\text { admission for remdesivir } \\
\text { giving symptom resolution. }\end{array}$ & $\begin{array}{l}\text { X-linked } \\
\text { agammaglobulinemia }\end{array}$ & $\begin{array}{l}\text { human normal } \\
\text { immunoglobulin }\end{array}$ \\
\hline 45 & 45 & 6 & Male & $\begin{array}{l}\text { Household tested positive two } \\
\text { weeks prior but no test sought } \\
\text { at time for participant. } \\
\text { Admission with anaemia for } \\
\text { two days with positive PCR } \\
\text { swab. Received one unit of } \\
\text { blood. Tests for leukaemia } \\
\text { relapse negative. }\end{array}$ & $\begin{array}{l}\text { acute lymphoblastic } \\
\text { leukaemia, asthma, } \\
\text { and autism }\end{array}$ & $\begin{array}{l}\text { mercaptopurine, } \\
\text { co-trimoxazole, } \\
\text { gabapentin, fluticasone } \\
\text { with salmeterol, } \\
\text { montelukast, } \\
\text { methotrexate, } \\
\text { macrogol, and } \\
\text { esomeprazole }\end{array}$ \\
\hline
\end{tabular}

Table 3

Cox hazard estimates for SARS-CoV-2 infection (controlling for other immunosuppressant treatment).

\begin{tabular}{|c|c|c|c|c|c|}
\hline Covariate & Coefficient & Standard error & $P$-value & Hazard Ratio & 95\% confidence interval HR \\
\hline Age & $0 \bullet 13$ & $0 \bullet 05$ & $0 \bullet 006$ & $1 \bullet 14$ & $1 \bullet 04-1 \bullet 25$ \\
\hline Immune deficiency & $1 \bullet 05$ & $0 \bullet 45$ & $0 \bullet 02$ & $2 \bullet 87$ & $1 \bullet 18-6 \bullet 94$ \\
\hline Worsening of fever in week of infection & $3 \cdot 25$ & $0 \bullet 75$ & $<0 \bullet 0001$ & $25 \bullet 79$ & $5 \bullet 94-112 \bullet 01$ \\
\hline Worsening of cough in week of infection & $2 \bullet 42$ & $0 \bullet 69$ & $0 \bullet 0005$ & $11 \bullet 29$ & $2 \cdot 91-43 \bullet 73$ \\
\hline Worsening of sore throat in week of infection & $2 \bullet 00$ & $0 \bullet 69$ & $0 \bullet 0037$ & $7 \bullet 41$ & $1 \bullet 92-28 \bullet 61$ \\
\hline
\end{tabular}


Table 4

Characteristics of participants participating in serology testing.

\begin{tabular}{|c|c|c|c|c|}
\hline & No serology & Serology & Positive serology & Negative serology \\
\hline Sample size & 1167 & 478 & 47 & 431 \\
\hline Female & $53 \bullet 6 \%$ & $56 \bullet 4 \%$ & $68 \bullet 1 \%$ & $55 \bullet 1 \%$ \\
\hline Teenagers & $52 \cdot 7 \%$ & $61 \bullet 0 \% * *$ & $80 \bullet 9 \% * *$ & $58 \bullet 8 \%$ \\
\hline $\begin{array}{l}\text { UK geography South } \\
\text { Middle North }\end{array}$ & $18 \bullet 6 \% 41 \bullet 3 \% 40 \bullet 1 \%$ & $22 \bullet 5 \% * 43 \bullet 3 \% 34 \bullet 2 \% *$ & $23 \bullet 4 \% 59 \bullet 6 \% * 17 \bullet 0 \% *$ & $22 \bullet 4 \% 41 \bullet 5 \% 36 \bullet 1 \%$ \\
\hline Age & $10 \bullet 5+4 \bullet 5$ & $11 \bullet 3+4 \bullet 2^{* * *}$ & $13 \bullet 5+3 \bullet 7^{* * * *}$ & $11 \bullet 1+4 \bullet 1$ \\
\hline Diagnosis & $12 \bullet 3 \% 9 \bullet 9 \% 7 \bullet 3 \%$ & $12 \bullet 5 \% 7 \bullet 6 \% 7 \bullet 8 \%$ & $17 \bullet 0 \% 12 \bullet 8 \% 17 \bullet 0 \% *$ & $12 \bullet 0 \% 7 \bullet 0 \% 6 \bullet 8 \%$ \\
\hline Gastroenterology & $6 \bullet 0 \% 9 \bullet 9 \% 6 \bullet 9 \% 8 \bullet 0 \%$ & $8 \bullet 7 \% * 7 \cdot 2 \% 7 \bullet 2 \%$ & $8 \bullet 5 \% 4 \bullet 3 \% 6 \bullet 4 \% 6 \bullet 4 \%$ & $8 \bullet 7 \% 7 \bullet 5 \% 7 \bullet 3 \% 9 \bullet 6 \%$ \\
\hline Nephrology & $25 \bullet 4 \% 35 \bullet 9 \% 16 \bullet 5 \%$ & $9 \bullet 3 \% 30 \bullet 0 \% 35 \bullet 5 \%$ & $25 \bullet 5 \% 38 \bullet 3 \% 19 \bullet 2 \%$ & $30 \bullet 5 \% 35 \bullet 2 \% 19 \bullet 0 \%$ \\
\hline $\begin{array}{l}\text { Transplants Diabetes } \\
\text { Immunodeficiency } \\
\text { Oncology Respiratory } \\
\text { Other Juvenile } \\
\text { Idiopathic Arthritis } \\
\text { Other immune } \\
\text { condition }\end{array}$ & & $19 \bullet 0 \%$ & & \\
\hline Medication Other & $45 \bullet 2 \% 0 \bullet 9 \% 15 \bullet 2 \%$ & $56 \bullet 6 \% * * * 0 \bullet 9 \% 15 \bullet 1 \%$ & $59 \bullet 5 \% 0 \% 11 \bullet 4 \%$ & $56 \bullet 3 \% 1 \bullet 0 \% 15 \bullet 5 \%$ \\
\hline drugs Chemotherapy & $17 \bullet 6 \% 16 \bullet 6 \% 29 \bullet 3 \%$ & $21 \bullet 0 \% 18 \bullet 9 \% 40 \bullet 9 \% * * *$ & $31 \bullet 9 \% * 27 \bullet 3 \% 43 \bullet 2 \%$ & $19 \bullet 8 \% 18 \bullet 0 \% 40 \bullet 7 \%$ \\
\hline $\begin{array}{l}\text { Antibiotics Other } \\
\text { immunosuppressants } \\
\text { Systemic } \\
\text { corticosteroids } \\
\text { Biologics Methotrexate }\end{array}$ & $24 \bullet 6 \%$ & $32 \bullet 1 \% * *$ & $22 \bullet 7 \%$ & $33 \bullet 2 \%$ \\
\hline
\end{tabular}

Statistics significance is calculated with Chi-Square statistics. If one or more cells in the contingency table had an expected count of less than five the Fisher's exact statistic was calculated. Group differences in age were calculated with $\mathrm{F}$ test.

* significant at $0 \bullet 05$ level.

** significant at $0 \bullet 01$ level.

*** significant at $0 \bullet 001$ level.

Table 5

Serology rates by vaccination status, sex, age group, and prior PCR status (only unvaccinated in the latter three tables).

\begin{tabular}{|c|c|c|c|c|c|c|}
\hline Prior vaccination status & anti-N IgG positive & anti-S1 IgG positive & Both positive & Seronegative & Totals & Total seropositive (\%) \\
\hline Vaccinated & 0 & 3 & 3 & 20 & 26 & $6(23 \bullet 1)$ \\
\hline Non-vaccinated & 21 & 7 & 13 & 411 & 452 & $41(9 \bullet 1)$ \\
\hline Totals & 21 & 10 & 16 & 431 & 478 & $47(9 \bullet 8)$ \\
\hline Sex & anti-N IgG positive & anti-S1 IgG positive & Both positive & Seronegative & Totals & Total seropositive (\%) \\
\hline Female & 15 & 4 & 10 & 223 & 252 & $29(11 \bullet 5)$ \\
\hline Male & 6 & 3 & 3 & 188 & 200 & $12(6)$ \\
\hline Totals & 21 & 7 & 13 & 411 & 452 & $41(9 \bullet 1)$ \\
\hline Age group & anti-N IgG positive & anti-S1 IgG positive & Both positive & Seronegative & Totals & Total seropositive (\%) \\
\hline $0-5$ years & 0 & 0 & 0 & 26 & 26 & $0(0)$ \\
\hline $6-10$ years & 5 & 0 & 2 & 125 & 132 & $7(5 \bullet 3)$ \\
\hline $11-15$ years & 7 & 2 & 5 & 167 & 181 & $14(7 \bullet 7)$ \\
\hline $16+$ years & 9 & 5 & 6 & 93 & 113 & $20(17 \bullet 7)$ \\
\hline Totals & 21 & 7 & 13 & 411 & 452 & $41(9 \bullet 1)$ \\
\hline Prior PCR status & anti-N IgG positive & anti-S1 IgG positive & Both positive & Seronegative & Totals & Total seropositive (\%) \\
\hline PCR positive & 4 & 1 & 4 & 9 & 18 & $9(50 \bullet 0)$ \\
\hline PCR negative & 17 & 6 & 9 & 402 & 434 & $32(7 \bullet 4)$ \\
\hline Totals & 21 & 7 & 13 & 411 & 452 & $41(9 \bullet 1)$ \\
\hline
\end{tabular}

anti-N and anti-S1 IgG. Associations were tested and are shown in Table 4. Detection of antibodies was associated with being female and over ten years old. Associations were also found with having had a transplant and being on immunosuppressants or corticosteroids. In those with prior positive PCR tests no associations were found between serology result and interval between positive test and serology test.

\section{Discussion}

We have demonstrated that this cohort of immunocompromised paediatric patients were at no increased risk of severe COVID-19 during the first two waves of the COVID-19 pandemic in the UK, supporting current NICE guidance. ${ }^{16}$

During the government-advised shielding period during the first wave of the pandemic, no participant reported a positive test for SARS-CoV-2, suggesting that shielding measures were effec- tive or testing capacity was insufficient. Subsequently, the peaks in cases in mid-November and late December in our cohort, correspond to peaks in overall UK prevalence and in paediatric prevalence in England during the second wave of the pandemic. ${ }^{33,34}$ The majority of those who did report positive PCR tests were managed at home. The four participants who reported hospital admission had diverse clinical presentations with none reporting admission due to acute severe COVID-19 or paediatric multisystem inflammatory syndrome (Table 2). No clear patterns or risk factors for admission are evident from data on those admitted. The presentations of anaemia in the participant with acute lymphoblastic leukaemia and delayed COVID lung changes in the participant with X-linked agammaglobulinemia supports ongoing vigilance for atypical COVID presentations in this diverse cohort. The reason participants were not at increased risk of severe disease is unclear. Children in general seem to be less affected and a potential additional factor may be that the participants chronic health conditions or 
medications, often immunosuppressive, reduce the risk of the excessive immune response that is a hallmark of severe COVID-19.

Increased hazard of SARS-CoV-2 infection with age is in keeping with overall paediatric rates reported in England and USA. ${ }^{2,35}$ This may represent increased symptom burden with age, as in the general paediatric population a bimodal distribution of severity has been observed with peaks in those under one year and over ten years. $^{2,14}$ It may also represent increased social mixing with age.

While immune deficiency was found to increase hazard of infection, there was no increased risk of admission in this group. This is a novel observation and has not been observed from ini$\mathrm{tial}^{36}$ or more recent data (Dr AM Shields, personal communication, July 2021) from the United Kingdom Primary Immunodeficiency Network. An Italian registry study including 1396 paediatric patients with primary immunodeficiency over one year from February 2020, found a lower incidence of infection $(33,2 \cdot 36 \%)$ compared to the general paediatric population. ${ }^{37}$ In a separate cohort, only three of 582 paediatric hospital admissions with SARSCoV-2 infection had immunodeficiency with none admitted to intensive care. ${ }^{14}$

Recognising symptoms of COVID-19 is a challenge in this population, due to symptom variability and overlap with those of chronic medical conditions. This study shows that in immunocompromised children, worsening of fever, cough, and sore throat were associated with a positive PCR test in the same week. Symptoms of fever and cough are common with SARS-CoV-2 infection and sore throat has been reported as being more common with the delta variant. ${ }^{38}$

\section{Serology}

While $9 \bullet 1 \%$ (41/452) of unvaccinated children and young people tested positive for antibodies reactive to SARS-CoV-2 in the serology sub-study, only $2 \cdot 5 \%$ (38/1527) reported positive SARS-CoV-2 PCR during the survey study. This suggests a proportion of participants had infection which was not confirmed by PCR test. Only 50\% $(9 / 18)$ of participants included in the serology sub-study who reported prior positive SARS-CoV-2 PCR tested positive for antibodies reactive to SARS-CoV-2. Half of PCR positive participants were not serologically positive when tested and some seroconverted with no prior detected infection. This may mean SARS-CoV-2 incidence was higher than reported here with participants having an infection undetected by PCR and serology.

Rates reported in this UK cohort are comparable to those $(6 \bullet 9 \%$, 68/992) reported in a cohort of children of UK healthcare workers during the first wave of the pandemic 2020. ${ }^{39}$ Other UK paediatric seroepidemiology studies have yet to be formally reported. ${ }^{26,27}$

The serology rates are comparable to a cross-sectional study in Madrid from September 2020 to February 2021 in paediatric rheumatology patients where $5 \bullet 7 \%(6 / 105)$ had PCR positive cases and $20 \cdot 0 \%(21 / 105)$ had serology positive cases with no overlap between these groups..$^{22}$ Our results are comparable to initial data from a prospective Belgian cohort study which reported $6 \bullet 0 \%$ $(15 / 250)$ serology positive participants in paediatric patients with chronic medical conditions. Only one seropositive participant, with a diagnosis of cystic fibrosis, required hospital admission while the rest were either asymptomatic or had mild symptoms. ${ }^{21}$

These rates are higher than observed in a cross sectional study from the USA from April 2020 to May 2020 and June 2020 to July 2020. In immunocompromised paediatric patients there were $1 \%$ (5/485) serology positive cases and $0 \bullet 4 \%$ (2/485) PCR positive cases with one of these in both groups. ${ }^{25}$

The reason for PCR positive cases not having detectable antibodies has not been established in our study and no associations are evident. Some evidence from inflammatory bowel disease patients suggests infliximab and other cytokine inhibitors may reduce seroconversion. $^{23,40}$ Of participants with negative serology tests but prior PCR confirmed SARS-CoV-2 infection, five had juvenile idiopathic arthritis, one immunodeficiency, and one type one diabetes. The remaining two are described in Table 2 as they reported admission with SARS-CoV-2 infection.

Limited conclusions can be drawn from serology in those who received a prior dose of a COVID vaccine given the single time point and short interval between vaccination and antibody testing.

\section{Limitations}

Limitations of our study include random censoring, due to late entry or withdrawal, which was experienced by $60 \%$ of participants. Due to this level of censoring, less confidence should be placed in results than the calculated confidence intervals. Questionnaire data is patient or parent reported and subject to recall bias, although we tried to minimize this by sending the questionnaire every week. Symptom over-reporting is possible, particularly in weeks when participants reported positive PCR tests. Symptom under-reporting is possible, particularly in participants with a baseline of symptoms from chronic disease, although less likely due to levels of anxiety in this cohort. ${ }^{18}$ Hazard of infection is likely over-estimated due to self-selection bias with participants presumably responding to surveys more frequently in weeks they reported a positive PCR swab. The shielding precautions taken will have varied both between individuals and through the course of the pandemic, so the individual hazard of SARS-CoV-2 infection will vary. The serology sub-study cohort was not representative of the overall study as described in the results section.

Following the study period reported here, in May 2021 the predominant strain in the UK became the Delta variant. There has been concern about the increased transmissibility and severity found in adults infected with the Delta variant. ${ }^{41}$ Fortunately, children have been shown to not be at increased risk of severe disease from it ${ }^{42}$. This emphasises the need for ongoing surveillance of the impact of variant strains on the risk to immunocompromised children.

\section{Conclusion}

Though cases of COVID-19 occurred in UK immunocompromised children and young people following the cessation of shielding measures, there was no increased risk of severe SARS-CoV2 infection in this large prospective national cohort. The serology results suggest that asymptomatic or unproven infection is quite common. Increasing age and immunodeficiency increased hazard of SARS-CoV-2 infection. Worsening of fever, cough, and sore throat were predictive of positive SARS-CoV-2 PCR.

\section{Contributors}

HC, RP, and HdG drafted and revised the manuscript. All authors reviewed and approved the final manuscript as submitted. HC, RP, CD, LM, MS, DG, AL, JSL, SNF, all ImmunoCOVID study group members and HdG contributed to the recruitment of participants. $\mathrm{CD}$ completed statistical analysis and contributed to the statistical analysis section and tables of the manuscript. AT, WI, PT, HJ, and TH-C completed laboratory analysis of serology samples and AT, WI, and PT contributed to the serology sections of the manuscript.

\section{Dissemination declaration}

We plan to disseminate the results to study participants and their parents. 


\section{Data sharing statement}

Research data may be made available upon reasonable request, wherever legally and ethically possible.

\section{Transparency declaration}

The Corresponding Author affirms that the manuscript is an honest, accurate, and transparent account of the study being reported. No important aspects of the study have been omitted. Any discrepancies from the study as planned have been explained.

\section{Exclusive license statement}

The Corresponding Author has the right to grant on behalf of all authors and does grant on behalf of all authors, a worldwide licence to the Publishers and its licensees in perpetuity, in all forms, formats, and media (whether known now or created in the future), to (i) publish, reproduce, distribute, display, and store the Contribution, (ii) translate the Contribution into other languages, create adaptations, reprints, include within collections, and create summaries, extracts and/or, abstracts of the Contribution, (iii) create any other derivative work(s) based on the Contribution, (iv) to exploit all subsidiary rights in the Contribution, (v) the inclusion of electronic links from the Contribution to third party material where-ever it may be located; and (vi) licence any third party to do any or all of the above.

\section{Funding}

A grant from the British Paediatric Allergy, Immunity and Infection Group and the NIHR Senior Investigator award to SNF supported participant recruitment and database management. Southampton Rheumatology Trust provided a grant to fund the cross sectional serology.

\section{Declaration of Competing Interest}

All authors have completed ICMJE disclosure forms. HdG received grant funding from the BPAIIG for the submitted work; there are no other relationships or activities that could appear to have influenced the submitted work.

\section{Acknowledgements}

We would like to acknowledge all the children, young people, and parents participating in this study. This study was badged as a UK NIHR Urgent Public Health Study and we would also like to thank the NIHR Clinical Research Network (CRN) and all associated NIHR Local CRNs and site staff who supported recruitment.

\section{Supplementary materials}

Supplementary material associated with this article can be found, in the online version, at doi:10.1016/j.jinf.2021.11.005.

\section{References}

1. Livingston E, Bucher K. Coronavirus disease 2019 (COVID-19) in Italy. JAMA 2020;323:1335.

2. CDC COVID-19 Response Team Coronavirus disease 2019 in children - United States, February 12-April 2, 2020. MMWR Morb Mortal Wkly Rep 2020;69:422-6.

3. Wu Z, McGoogan JM. Characteristics of and important lessons from the coronavirus disease 2019 (COVID-19) outbreak in China: summary of a report of 72314 cases from the Chinese center for disease control and prevention. JAMA 2020;323:1239-42.

4. de Lusignan S, Dorward J, Correa A, Jones N, Akinyemi O, Amirthalingam G, et al. Risk factors for SARS-CoV-2 among patients in the Oxford Royal College of General Practitioners Research and Surveillance Centre primary care network: a cross-sectional study. Lancet Infect Dis 2020;20:1034-42.
5. Swann OV, Holden KA, Turtle L, Pollock L, Fairfield CJ, Drake TM, et al. Clinical characteristics of children and young people admitted to hospital with covid-19 in United Kingdom: prospective multicentre observational cohort study. BMJ 2020;370:m3249.

6. Ladhani SN, Amin-Chowdhury Z, Amirthalingam G, Demirjian A, Ramsay ME. Prioritising paediatric surveillance during the COVID-19 pandemic. Arch Dis Child 2020:105:613-15.

7. Public Health England. SARS-CoV2 Susceptibility and Transmission Risk in Children: an Overview of Current Evidence from Public Health England's Surveillance Work. Public Health England; 2020. Sep 11 https://assets.publishing. service.gov.uk/government/uploads/system/uploads/attachment_data/file/916891/ phe-susceptibility-transmission-children-s0717-sage-53-200819.pdf (accessed July 19, 2021).

8. Smith BK, Janowski AB, Danis JE, Harvey IB, Zhao H, Dai Y-N, et al. Seroprevalence of SARS-CoV-2 antibodies in children and adults in St. Louis, Missouri, USA. mSphere 2021;6:e01207-20.

9. He Z, Ren L, Yang J, Guo L, Feng L, Ma C, et al. Seroprevalence and humoral immune durability of anti-SARS-CoV-2 antibodies in Wuhan, China: a longitudinal, population-level, cross-sectional study. Lancet 2021;397:1075-84.

10. Stringhini S, Wisniak A, Piumatti G, Azman AS, Lauer SA, Baysson H, et al. Seroprevalence of anti-SARS-CoV-2 IgG antibodies in Geneva, Switzerland (SEROCoV-POP): a population-based study. Lancet 2020;396:313-19.

11. Stringhini S, Zaballa ME, Perez-Saez J, Pullen N, de Mestral C, Picazio A, et al. Seroprevalence of anti-SARS-CoV-2 antibodies after the second pandemic peak. Lancet Infect Dis 2021;21:600-1.

12. Public Health England. National COVID-19 Surveillance Report. Public Health England; 2020. 17 July(week 29) https://assets.publishing.service. gov.uk/government/uploads/system/uploads/attachment data/file/901803/ Weekly_COVID19_Surveillance_Report_week_29_FINAL.pdf (accessed July 19 2021,).

13. Bailey LC, Razzaghi H, Burrows EK, Bunnell HT, Camacho PEF, Christakis DA et al. Assessment of 135794 pediatric patients tested for severe acute respiratory syndrome coronavirus 2 across the United States. JAMA Pediatr 2021; 175:176-84

14. Götzinger F, Santiago-García B, Noguera-Julián A, Lanaspa M, Lancella L, Calò Carducci FI, et al. COVID-19 in children and adolescents in Europe: a multinational, multicentre cohort study. Lancet Child Adolesc Health 2020;4:653-61.

15. Bhopal SS, Bagaria J. Olabi B, Bhopal R. Children and young people remain at low risk of COVID-19 mortality. Lancet Child Adolesc Health 2021;5:e12-ee3.

16. NICE. COVID-19 Rapid Guideline: Children and Young People who are Immunocompromise. NICE; 2020. GuidelineAug 14 https://www.nice.org.uk/guidance/ng174 (accessed July 19, 2021)

17. Connelly JA, Chong H, Esbenshade AJ, Frame D, Failing C, Secord E, et al. Impact of COVID-19 on pediatric immunocompromised patients. PREPROOF. Pediatr Clin North Am 2021;68:1029-54.

18. Shaunak M, Patel R, Driessens C, Mills L, Leahy A, Gbesemete D, et al. COVID-19 symptom surveillance in immunocompromised children and young people in the UK: a prospective observational cohort study. BMJ Open 2021;11:e044899.

19. Tsankov BK, Allaire JM, Irvine MA, Lopez AA, Sauvé LJ, Vallance BA, et al. Severe COVID-19 infection and pediatric comorbidities: a systematic review and meta-analysis. Int J Infect Dis 2021;103:246-56.

20. Kompaniyets L, Agathis NT, Nelson JM, Preston LE, Ko JY, Belay B, et al. Underlying Medical conditions associated with severe COVID-19 illness among children. JAMA Netw Open 2021;4:e2111182.

21. Hoste L, Prytula-Ebels A, Dehoorne J, De Bruyne R, Van Biervliet S, De Waele K, et al. SeroCovid19: prospective seroprevalence monitoring reveals substantially reduced SARS-CoV-2 infection rate among tertiary pediatric patients. Presented at BVK-SBP 49th annual congress of the Belgian Society of Pediatrics. Abstract published in. Belg J Paediatr 2021;23(Supplement 1):93. May 3 http: //hdl.handle.net/1854/LU-8706240 (accessed July 19, 2021).

22. Clara U, Claudia ML, Celia P, Laura V, Iker FR, Celia M, et al. Clinical course and seroprevalence of COVID-19 in children with rheumatic diseases. Cross-sectional study from a reference centre in Spain. PREPRINT (Version 1). Res Sq 2021.

23. Kennedy NA, Goodhand JR, Bewshea C, Nice R, Chee D, Lin S, et al. Anti-SARSCoV-2 antibody responses are attenuated in patients with IBD treated with infliximab. Gut 2021:70:865-75.

24. Alshami A, Al Attas R, Azzam A, Mohammed A, Al-Quhaidan N. Detection of SARS-CoV-2 antibodies in pediatric kidney transplant patients. BMC Nephrol $2021 ; 22: 123$.

25. Freeman MC, Rapsinski GJ, Zilla ML, Wheeler SE. Immunocompromised seroprevalence and course of illness of SARS-CoV-2 in one pediatric quaternary care center. J Pediatric Infect Dis Soc 2021;10:426-31.

26. Oxford Vaccine Group. What's the STORY? Oxford Vaccine Group; 2021. Feb 17 https://whatsthestory.web.ox.ac.uk/home (accessed July 19, 2021).

27. Public Health England. COVID-19: Paediatric Surveillance. 7. Serosurveys in Children. Public Health England; 2021. May 4 https://www.gov.uk/guidance/ covid-19-paediatric-surveillance\#serosurveys-in-children (accessed July 19, 2021).

28. Public Health England. The Green Book of Immunisation, Chapter 19 Influenza. Public Health England; Oct 29, 2020 https://assets.publishing. service.gov.uk/government/uploads/system/uploads/attachment data/file/931139/ Green_book_chapter_19_influenza_V7_OCT_2020.pdf (accessed July 19, 2021).

29. ISARIC/WHO. Clinical Characterisation Protocol (CCP). ISARIC/WHO; 2021. Jan 23 https://isaric.net/ccp (accessed July 19, 2021).

30. Department of Health and Social Care. Everyone in the United Kingdom with Symptoms Now Eligible for Coronavirus Tests. Department of Health and Social Care; 2021. May 20 https://www.gov.uk/government/news/ 
everyone-in-the-united-kingdom-with-symptoms-now-eligible-for-coronavirus-tests (accessed July 19, 2021)

31. Department of Health and Social Care. Government Launches NHS Test and Trace Service. Department of Health and Social Care; 2020. May 27 https: //www.gov.uk/government/news/government-launches-nhs-test-and-trace-service (accessed July 19, 2021).

32. Tighe PJ, Urbanowicz RA, Fairclough CL, McClure CP, Thomson BJ, Gomez N, et al. Potent Anti-SARS-CoV-2 Antibody Responses are Associated with Better Prognosis in Hospital Inpatient COVID-19 Disease. medRxiv; 2020. PREPRINT202008.22.

33. Office for National Statistics. Coronavirus (COVID-19) Infection Survey, UK: 18 December 2020. Office for National Statistics; 2020. Dec 18 https://www.ons.gov.uk/peoplepopulationandcommunity/healthandsocialcare/ conditionsanddiseases/bulletins/coronaviruscovid19infectionsurveypilot/

18december2020\#age-analysis-of-the-number-of-people-in-england-who-had-covid-19 (accessed July 19, 2021).

34. Office for National Statistics. Coronavirus (COVID-19) Infection Survey, UK: 22 January 2021. Office for National Statistics; 2021. Jan 22 https://www.ons.gov.uk/peoplepopulationandcommunity/healthandsocialcare/ conditionsanddiseases/bulletins/coronaviruscovid19infectionsurveypilot/

22january2021\#age-analysis-of-the-number-of-people-in-england-who-had-covid-19 (accessed July 19, 2021).

35. Public Health England. Weekly National INFLUENZA and COVID-19 Surveillance Report. Public Health England; 2021. Week 27 report (up to week 26 data)July 8 https://assets.publishing.service.gov.uk/government/uploads/system/ uploads/attachment_data/file/1000373/Weekly_Flu_and_COVID-19_report_w27.pdf (accessed July 19, 2021).
36. Shields AM, Burns SO, Savic S, Richter AG. COVID-19 in patients with primary and secondary immunodeficiency: the United Kingdom experience. J Allergy Clin Immunol 2021;147:870-5 e1.

37. Milito C, Lougaris V, Giardino G, Punziano A, Vultaggio A, Carrabba M, et al. Clinical outcome, incidence, and SARS-CoV-2 infection-fatality rates in Italian patients with inborn errors of immunity. J Allergy Clin Immunol Pract 2021;9:2904-6 e2.

38. Office for National Statistics. Coronavirus (COVID-19) Infection Survey: Characteristics of People Testing Positive for COVID-19 in England. Office for National Statistics; 2021. 27 January 2021Jan 27 https://www.ons.gov. uk/peoplepopulationandcommunity/healthandsocialcare/conditionsanddiseases/ articles/coronaviruscovid19infectionsinthecommunityinengland/ characteristicsofpeopletestingpositiveforcovid19inengland27january2021 (accessed July 19, 2021).

9. Waterfield T, Watson C, Moore R, Ferris K, Tonry C, Watt A, et al. Seroprevalence of SARS-CoV-2 antibodies in children: a prospective multicentre cohort study. Arch Dis Child 2021;106:680-6.

40. Simon D, Tascilar K, Krönke G, Kleyer A, Zaiss MM, Heppt F, et al. Patients with immune-mediated inflammatory diseases receiving cytokine inhibitors have low prevalence of SARS-CoV-2 seroconversion. Nat Commun 2020;11:3774.

41. Twohig KA, Nyberg $T$, Zaidi A, Thelwall S, Sinnathamby MA, Aliabadi S, et al. Hospital admission and emergency care attendance risk for SARS-CoV-2 delta (B.1.617.2) compared with alpha (B.1.1.7) variants of concern: a cohort study. Lancet Infect Dis 2021.

42. Molteni E, Sudre CH, Canas LS, Bhopal SS, Hughes RC, Chen L, et al. Illness Characteristics of COVID-19 in Children Infected with the SARS-CoV-2 Delta Variant. medRxiv; 2021. 2021.10.06. 